\title{
CONTAMINANT UPTAKE BY FISH AND THE POTENTIAL FOR TRANSFER TO HUMANS MODELLED OVER TIME
}

\author{
A.L. JENSEN \\ School of Natural Resources, University of Michigan, Ann Arbor, MI 48109 (U.S.A.) \\ (Accepted 20 June 1985)
}

\begin{abstract}
Jensen. A.L., 1986. Contaminant uptake by fish and the potential for transfer to humans modelled over time. Ecol. Modelling. 32: 281-290.

A model is developed that enables coupling of contaminant uptake with the growth dynamics of fish, exploitation, and transfer and fate. Contaminant concentration in fish is a function of the properties of the contaminant, concentrations in their food and water. of their growth dynamics, and of the level of exploitation. Exploitation has a large effect on the size and age structure of exploited populations and, therefore, it also has a large effect on contaminant concentrations and potential rates of transfer to humans. It is essential that the biological component of transfer and fate models describe these aspects of contaminant uptake but at the same time the model must be relatively simple and describe uptake as a function of time rather than age.
\end{abstract}

\section{INTRODUCTION}

The level of contaminants, such as PCBs, in fish is determined by the bioenergetics and growth in size of fish as well as by properties of the contaminants. The more successful models for contaminant uptake, such as the Norstrom et al. (1976) model and the adaptation of the Norstrom et al. (1976) model developed by Jensen et al. (1982) and Jensen (1984), model uptake as a function of age. It is difficult to couple a model for uptake by a cohort with transfer and fate models such as those developed by Neely (1976) and Schnoor (1981) where processes are modelled as functions of time. In transfer and fate models the biological component is usually described with simplicity and such models are of limited value in assessing options that might be taken to minimize exposure of humans to contaminants.

In this study a model similar to the Norstrom et al. (1976) model is developed and applied for description of contaminant uptake as a function 
of time; the model maintains the necessary and important link to size and age structure. The new model is coupled with surplus production model that is applied for fishery management. It also can be coupled with transfer and fate models.

The model is applied to simulate the dynamics of PCB uptake by lake trout (Salvelinus namaycush) of the Great Lakes.

\section{DEVELOPMENT OF MODEL FOR CONTAMINANT UPTAKE}

A model for change in body burden as a function of time is obtained from the Norstrom et al. (1976) model, which describes uptake as a function of age, by summing over individuals. The change in body burden of a contaminant over age for an individual fish is described by the general bioenergetics based mass balance equation (Norstrom et al., 1976):

$\mathrm{d} p / \mathrm{d} x=e_{\mathrm{pf}} C_{\mathrm{f}} R+e_{\mathrm{pw}} C_{\mathrm{w}} V-k p W^{\xi}$

where $x=$ age in years; $p=$ body burden of contaminant in an individual fish of age $x(\mathrm{~g}) ; e_{\mathrm{pf}}=$ efficiency of uptake of contaminant from food; $e_{\mathrm{pw}}=$ efficiency of uptake of contaminant from water; $R=$ ratio (g/week); $C_{\mathrm{f}}=$ concentration of the contaminant in food $(\mathrm{g} / \mathrm{g}) ; C_{\mathrm{w}}=$ concentration of the contaminant in water $(\mathrm{g} / \mathrm{g}) ; V=$ volume of water passing gills $(\mathrm{g} /$ week $)$; $W=$ wet weight of an individual fish $(\mathrm{g}) ; k=$ clearance coefficient $\left(\mathrm{g}^{-\xi} /\right.$ week $) ; \xi=$ exponent of body weight in the clearance term.

Let $p_{i}$ be the body burden in the $i$ th individual in a population of size $N$, then applying the additive rule for the derivative gives:

$$
\sum_{i=1}^{N} \frac{\mathrm{d} p_{i}}{\mathrm{~d} t}=e_{\mathrm{pf}} C_{\mathrm{f}} \sum_{i=1}^{N} R_{i}+e_{\mathrm{pw}} C_{\mathrm{w}} \sum_{i=1}^{N} V_{i}-\sum_{i=1}^{N} p_{i} W_{i}
$$

where $P$ is the total body burden of the population at time $t$. For the population at a point in time the change in body burden is:

$$
\sum_{i=1}^{N} \frac{\mathrm{d} p_{i}}{\mathrm{~d} t}=\frac{\mathrm{d} \sum p_{i}}{\mathrm{~d} t}=\frac{\mathrm{d} P}{\mathrm{~d} t}
$$

where $R_{i}, V_{i}, p_{i}$, and $W_{i}$ are the ration, volume of oxygen flow over the gills, body burden, and weight for the $i$ th individual.

To apply equation (3) expressions for ratio and for the volume of water passing over the gills are necessary. An expression for ratio can be developed from the energy balance equation:

$e_{\mathrm{f}} q_{\mathrm{f}} R=Q+q_{\mathrm{a}} \mathrm{d} W / \mathrm{d} t$

which states that the energy consumed by an animal equals the energy 
expended, where the new terms are: $Q=$ total metabolic rate ( $\mathrm{J} /$ week); $q_{\mathrm{a}}=$ joule equivalent of animal accumulating pollutant $(\mathrm{J} / \mathrm{g}) ; q_{\mathrm{f}}=$ joule equivalent of food $(\mathrm{J} / \mathrm{g}) ; e_{\mathrm{f}}=$ efficiency of assimilation of metabolizable energy from food.

Norstrom et al. (1976) separated total metabolic rate into a low routine metabolic rate $Q_{\mathrm{Ir}}$, which includes the standard metabolic rate and the energy cost of spontaneous activity, and into the energy cost specific to utilization of food, $Q_{\mathrm{s}}$. Application of the conventional metabolic expressions $Q_{\mathrm{lr}}=\alpha W^{\gamma}$ and $Q_{\mathrm{s}}=\beta q_{\mathrm{a}} \mathrm{d} W / \mathrm{d} t$ for these components gives for an individual the ration:

$R=\frac{1}{e_{\mathrm{r}} q_{\mathrm{d}}}\left[\alpha W_{i}^{\gamma}+q_{\mathrm{a}}(1+\beta) \frac{\mathrm{d} W_{i}}{\mathrm{~d} t}\right]$

For all members of the population at time $t$ the total ration is:

$\sum_{i=1}^{N} R_{i}=\frac{1}{e_{\mathrm{f}} q_{\mathrm{f}}}\left[\sum_{i=1}^{N} \alpha W_{i}^{\gamma}+q_{\mathrm{a}}(1+\beta) \sum_{i=1}^{N} \frac{\mathrm{d} W_{i}}{\mathrm{~d} t}\right]$

Let $\bar{W}$ be the average size of an individual in the population, then $\Sigma W=N \bar{W}$. and as an approximation take:

$$
\sum_{i=1}^{N} W_{i}^{\gamma}=N \bar{W}^{\gamma} a
$$

where $a$ is a constant. The above equation is exact if $\gamma=1$, and the average metabolic parameter $\gamma$ is about 0.92 (Glass, 1969). Simulations indicate that for $\gamma=0.92$ the value of $a$ is close to 1.14.

The sum of the derivatives of weights can be written in terms of biomass as:

$\sum_{i=1}^{N} \frac{\mathrm{d} W_{i}}{\mathrm{~d} t}=\frac{\mathrm{d} \sum W_{i}}{\mathrm{~d} t}=\frac{\mathrm{d} B}{\mathrm{~d} t}$

Therefore, the total ration can be expressed in terms of average weight and biomass as:

$\sum_{i=1}^{N} R_{i}=\frac{1}{e_{\mathrm{f}} q_{\mathrm{f}}}\left[\alpha a N \bar{W}^{\gamma}+q_{\mathrm{a}}(1+\beta) \frac{\mathrm{d} B}{\mathrm{~d} t}\right]$

An expression for the volume of water passing over the gills is given by the relation between the amount of oxygen necessary to satisfy metabolic demand and the volume of water containing this quantity of oxygen. which is (Norstrom et al., 1976):

$Q=e_{\mathrm{ox}} C_{\mathrm{ox}} G_{\mathrm{ox}} V$ 
where: $e_{\mathrm{ox}}=$ efficiency of assimilation of oxygen by the gills; $C_{\mathrm{ox}}=$ concentration of oxygen in the water $(\mathrm{g} / \mathrm{g}) ; q_{\mathrm{ox}}=$ joule equivalent of oxygen $(\mathrm{J} / \mathrm{g})$. This gives the relation for the volume of water passing over the gills of an individual as:

$V=\frac{Q}{e_{\mathrm{ox}} C_{\mathrm{ox}} q_{\mathrm{ox}}}$

and applying expressions developed above for the metabolic terms, the volume for the population is:

$$
\sum_{i=1}^{N} V_{i}=\frac{a N \bar{W}^{\gamma}+\beta q_{\mathrm{a}} \mathrm{d} B / \mathrm{d} t}{e_{\mathrm{ox}} C_{\mathrm{ox}} q_{\mathrm{ox}}}
$$

The expression for elimination for the population is:

$-k \sum_{i=1}^{N} p_{i} W_{i}^{\xi}$

Assuming an average contaminant concentration per individual, $\bar{p}$, equation (13) becomes:

$$
-k \bar{p} \sum_{i=1}^{N} W=-k \bar{p} N \bar{W}^{\gamma} a
$$

Combining the above equations gives the change in total body burden of the population with respect to time as:

$$
\begin{aligned}
\mathrm{d} P / \mathrm{d} t= & \frac{e_{\mathrm{pf}} C_{\mathrm{f}}}{e_{\mathrm{f}} q_{\mathrm{f}}}\left[\alpha a N \bar{W}^{\gamma}+q_{\mathrm{a}}(1+\beta) \frac{\mathrm{d} B}{\mathrm{~d} t}\right] \\
& +\frac{e_{\mathrm{pw}} C_{\mathrm{w}}}{e_{\mathrm{ox}} C_{\mathrm{ox}} q_{\mathrm{ox}}}\left[\alpha a N \bar{W}^{\gamma}+\beta q_{\mathrm{a}} \frac{\mathrm{d} B}{\mathrm{~d} t}\right]-k a \bar{p} N \bar{W}^{\xi}
\end{aligned}
$$

\section{COUPLING CONTAMINANT UPTAKE AND SURPLUS PRODUCTION MODELS}

The above equation for contaminant uptake can be coupled to the surplus production model, a model which is applied to model yield from a fishery. The coupled model can be applied to obtain estimates of stock biomass, $B$, yield from the fishery, $Y$, and the potential for transfer of contaminants from fish to humans. For the logistic surplus production model the yield equation and equation for change in biomass of the fish stock over time are (Jensen, 1976, 1978):

$\mathrm{d} Y / \mathrm{d} t=q E B$

$\mathrm{d} B / \mathrm{d} t=r B-r B^{2} / B_{\infty}-q E B$ 
where $Y=$ yield $(\mathrm{kg}) ; B=$ biomass of the stock $(\mathrm{kg}) ; r=$ coefficient for increase in population size (per year); $q=$ a catchability coefficient (per effort time); $B_{\infty}=$ the environmental carrying capacity $(\mathrm{kg}) ; E=$ fishing effort. With the surplus production model it can be shown that yield $(\mathrm{kg})$ from a fishery is given by the parabola:

$Y_{\mathrm{e}}=B_{\infty} F-B_{\infty} F^{2} / r$

and the total quantity of contaminant transferred $(\mathrm{kg})$ from fish to humans is:

$T=C_{\text {fish }} Y_{\mathrm{e}}$

Exploitation results in considerable change in the age and size structure of a population but usually these are not considered when the surplus production model is applied. Fisheries are usually assessed with the surplus production model under the assumption of equilibrium and the uptake model will be applied assuming that $\mathrm{d} B / \mathrm{d} t=0$ and $\mathrm{d} P / \mathrm{d} t=0$. At equilibrium the average body burden of an individual is:

$\bar{p}=\frac{1}{k \bar{W}^{\xi}}\left[\frac{e_{\mathrm{f}} C_{\mathrm{w}} \bar{A}^{\gamma}}{e_{\mathrm{ox}} C_{\mathrm{ox}} q_{\mathrm{ox}}}+\frac{C_{\mathrm{f}} \bar{W}^{\gamma}}{e_{\mathrm{f}} q_{\mathrm{f}}}\right]$

and the concentration in fish is $C_{\text {fish }}=\bar{p} / \bar{W}$.

Equation (15) enables consideration of the change in contaminant level with change in age structure and average size. The weight of an individual of age $x$ is given by the Von Bertalanffy equation (Ricker, 1975):

$W(x)=W_{\infty}\left[1-\mathrm{e}^{-K\left(x-x_{0}\right)}\right]^{3}$

where: $W_{\infty}=$ the asymptotic weight $(\mathrm{g}) ; K=$ growth coefficient (per year); $x_{0}=$ theoretical age when size is zero (years). The abundance of individuals of age $x$ is (Ricker, 1975):

$N(x)=R \mathrm{e}^{-(F+M)\left(x-x_{\mathrm{r}}\right)}$

where $F=q E$ is the fishing mortality coefficient, $M$ is the natural mortality coefficient, and $x_{\mathrm{r}}$ is the age ate recruitment. The average weight of an individual in a population is:

$\bar{W}=\frac{\int_{x_{\mathrm{r}}}^{x_{\mathrm{v}}} W N \mathrm{~d} z}{\int_{x_{\mathrm{r}}}^{x_{\mathrm{v}}} N \mathrm{~d} x}=\frac{\int_{x_{\mathrm{r}}}^{x_{\mathrm{v}}} W_{\infty} \mathrm{e}^{-(F+M)\left(x-x_{0}\right)}\left[1-\mathrm{e}^{-K\left(x-x_{i j}\right)}\right]^{2} \mathrm{~d} x}{\int_{x_{\mathrm{r}}}^{x_{\mathrm{v}}} \mathrm{e}^{-(F+M)\left(x-x_{i n}\right)} \mathrm{d} z}$

and integration gives:

$\bar{W}=\frac{(F+M) W_{\infty} \sum \frac{U_{n}}{F+M+n K} \mathrm{e}^{-n K\left(x_{\mathrm{r}}-x_{(1)}\right)}\left[1-\mathrm{e}^{-(F+M+n K)\left(x_{\mathrm{r}}-x_{(1)}\right)}\right]}{1-\mathrm{e}^{-(F+M)\left(x_{\mathrm{r}}-x_{\mathrm{r}}\right)}}$

where $U=1, U=-3, U=3$, and $U=-1$. 


\section{RESULTS AND DISCUSSION}

The coupled model was applied to describe the dynamics of uptake and the potential for transfer to humans of PCBs by lake trout (Salvelinus namaycush) of the North American Great Lakes. Contamination of fishes with PCBs has been a persistent problem on the Great Lakes. A detailed description of the data is given by Jensen et al. (1982). Different components of the above model have been applied separately to the take trout fishery and all of the model parameters have been estimated. The metabolic parameters are given by Norstrom et al. (1976), Jensen et al. (1982), and Jensen (1984). The concentration of PCBs in food of lake trout was $3 \mathrm{mg} / \mathrm{kg}$ and the concentration in the water was $10 \mathrm{ng} / \mathrm{l}$ (Jensen et al., 1982). The growth parameters are $x_{0}=0$ years, $K=0.14$ per year, and $W_{\infty}=7.34 \mathrm{~kg}$ (Jensen et al., 1982) and the mortality parameters are $F=0.50$ per year, $x_{\mathrm{r}}=4$ years, and $M=0.20$ per year (Jensen et al., 1982). The surplus production model was fitted to lake trout data for Lake Superior (Jensen, 1978); the parameter estimates were $r=0.48$ per year, $B_{\infty}=1411774 \mathrm{~kg}$, and $q=0.00001$ per $1000 \mathrm{ft}(3048 \mathrm{~m})$ of gill net per year. The parameter estimates are summarized in Table 1.

To evaluate the simulation results, they are compared with results obtained using the Norstrom et al. (1976) model coupled to the dynamic pool

\section{TABLE 1}

Description of model parameters and estimates

\begin{tabular}{lll}
\hline Symbol & Description & Value \\
\hline$e_{\mathrm{pf}}$ & Efficiency of assimilation of toxicant from food & 0.82 \\
$e_{\mathrm{f}}$ & Efficiency of assimilation of metabolizable energy from food & 0.80 \\
$e_{\mathrm{pw}}$ & Efficiency of assimilation of xicant from water & 0.75 \\
$\gamma$ & Exponent of body weight for metabolism & 0.92 \\
$C_{\mathrm{ox}}$ & Concentration of oxygen in the water & $9.20 \times 10^{-6} \mathrm{~g} / \mathrm{g}$ \\
$q_{\mathrm{ox}}$ & Joule equivalent of oxygen & $1.43 \times 10^{4} \mathrm{~J} / \mathrm{g}$ \\
$k$ & Clearance coefficient & $0.238 \mathrm{~g} / \mathrm{week}$ \\
$\xi$ & Exponent of body weight in clearance equation & 0.58 \\
$\alpha$ & Low-routine metabolism & $502.8 \mathrm{~J} \mathrm{week}{ }^{-1} \mathrm{~g}^{-1}$ \\
$q_{\mathrm{f}}$ & Joule equivalent of food & $4190 \mathrm{~J} / \mathrm{g}$ \\
$C_{\mathrm{W}}$ & PCB concentration in water & $10 \mathrm{ng} / 1$ \\
$C_{\mathrm{f}}$ & PCB concentration in food & $3 \mathrm{mg} / \mathrm{kg}$ \\
$W_{\infty}$ & Asymptotic weight & $7.34 \mathrm{~kg}$ \\
$K$ & Growth rate coefficient & $0.14 \mathrm{per}$ year \\
$F$ & Instantaneous fishing mortality coefficient & $0.50 \mathrm{per} \mathrm{year}$ \\
$x_{\mathrm{r}}$ & Age at recruitment & 4 years \\
$M$ & Natural mortality coefficient & $0.20 \mathrm{per}$ year \\
$a$ & Constant & 1.14 \\
\hline
\end{tabular}




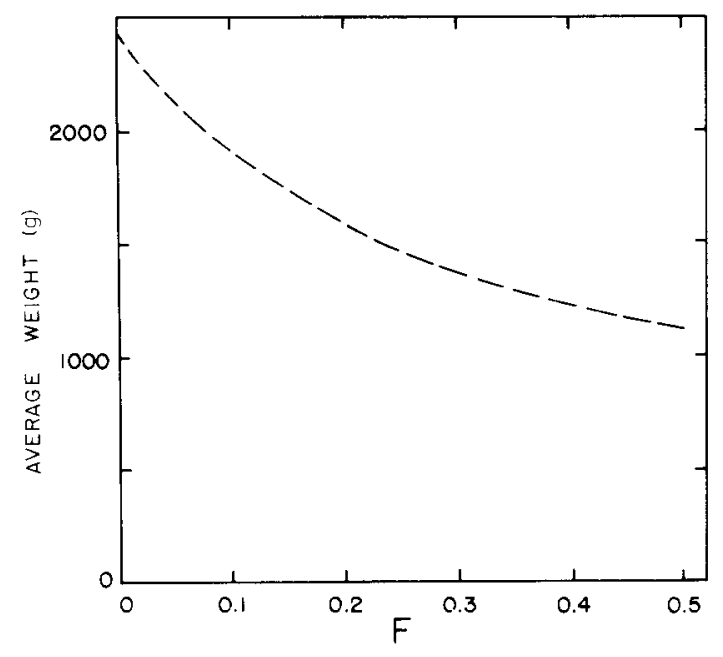

Fig. 1. Relation between instantaneous fishing mortality coefficient per year $(F)$ and average weight of lake trout.

yield equation (Jensen, 1984). As fishing mortality increases the average weight of individuals in a population decreases exponentially (Fig. 1). The average level of fishing mortality for lake trout is 0.40 per year (Healey, 1978) and at this level of mortality the average size of a lake trout in the population is about 50\% lower than the average size in an unexploited population; size decreases from nearly $2500 \mathrm{~g}$ in an unexploited population to about $1200 \mathrm{~g}$. This general pattern of a decrease in size with exploitation is well known and was described by Beverton and Holt (1957).

The PCB body burden increases rapidly with increase in average weight (Fig. 2). The relation between average weight and PCB concentration is considerably different from that between individual weight and concentration reported by Jensen et al. (1982). The average weight of an individual in a population is relatively small because abundance decreases exponentially with age and there is a large number of younger and smaller fish. The concentrations of PCBs at values of $W$ are higher than those for individual weights because even when $W$ is small there are older and larger individuals in the population with high PCB concentrations. The pattern of increase in $\mathrm{PCB}$ concentration with an increase in $W$ is consistent with that reported by Jensen et al. (1982).

The change in PCB concentration with increase in fishing mortality can be compared directly with the result obtained by Jensen (1984) using a dynamic pool model coupled with the Norstrom et al. (1976) model and the results obtained by Jensen (1984) are nearly identical to those obtained here (Fig. 3) with the surplus production model. As the rate of exploitation 


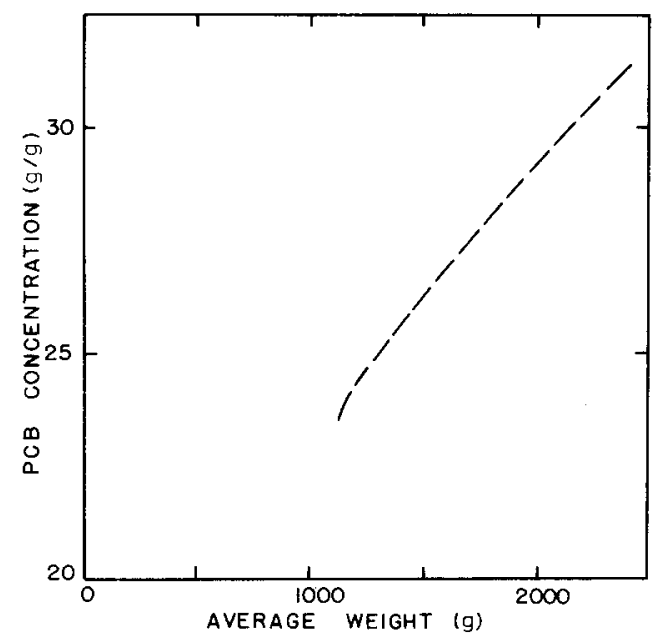

Fig. 2. Relation between average weight of a lake trout and $\mathrm{PCB}$ concentration.

increases the concentration of PCBs decreases exponentially because of the change in size and age composition of the population caused by exploitation. At the average level of exploitation for lake trout of 0.4 the PCB concentration has decreased from greater than $30 \mathrm{~g} / \mathrm{g}$, the concentration in an unexploited population, to less than $25 \mathrm{~g} / \mathrm{g}$.

The yield curve and the curve for transfer of contaminants from fishes to human for the surplus production model are considerably different from

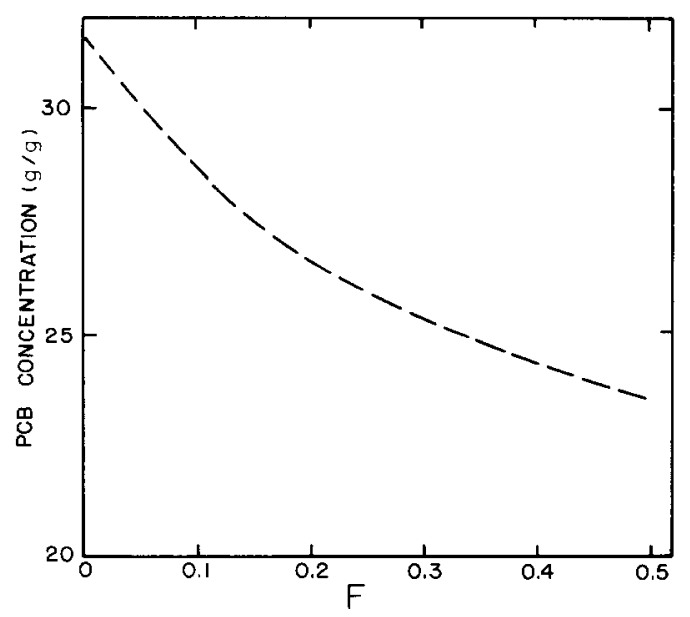

Fig. 3. Relation between instantaneous fishing mortality coefficient per year $(F)$ and average $\mathrm{PCB}$ concentration per individual fish. 


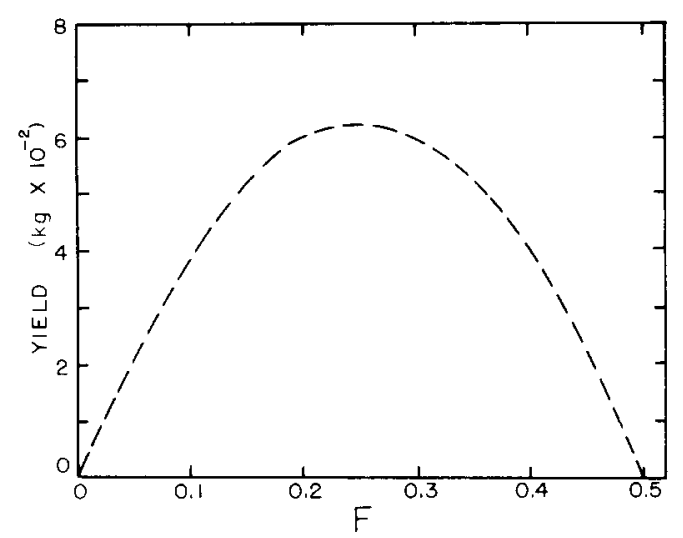

Fig. 4. RElation between instantaneous fishing mortality coefficient per year $(F)$ and yield for lake trout.

those of the dynamic pool model reported by Jensen (1984). The logistic surplus production model predicts that yield and fishing effort are related by a parabola (Fig. 4) and as fishing effort increases yield from the fishery increases to a maximum and then begins to decrease. The dynamic pool model predicts a maximum yield, but it indicates that with overexploitation yield does not decrease so quickly (Jensen, 1984).

The total amount of contaminant that could be transferred from fish to humans with increase in exploitation follows a curve very similar to the yield curve (Fig. 5). The maximum amount that could be transferred occurs at a fishing mortality slightly less than the fishing mortality at which the maxi-

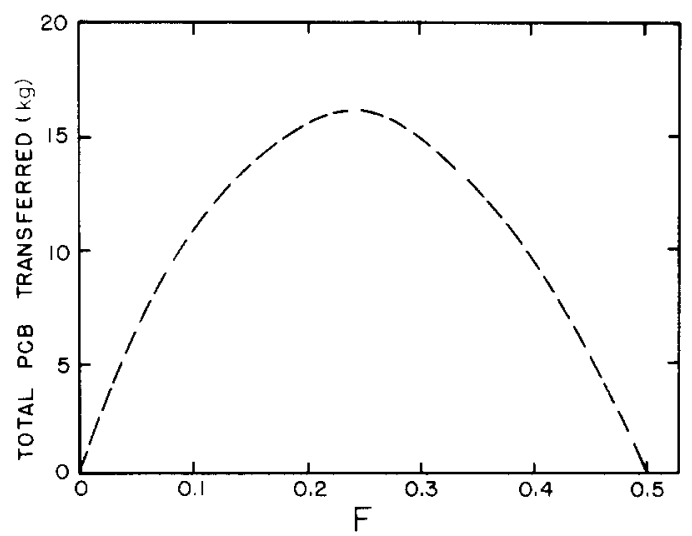

Fig. 5. Relation between instantaneous fishing mortality coefficient per year $(F)$ and total amount of PCB transferred from fish to humans. 
mum yield occurs and the contaminant transfer curve is slightly to the left of the yield curve because of the decreasing number of older and more highly contaminated fish as exploitation increases. At the average level of exploitation reported for lake trout the amount of contaminant that could be transferred is considerably less than the amount that could be transferred at the maximum sustainable yield.

\section{REFERENCES}

Beverton, R.J.H. and Holt, S.J., 1957. On the dynamics of exploited fish population. U.K. Minist. Agric. Fish., Fish. Invest. (Ser. 2), 19.

Glass, N.R., 1969. Discussion of calculations of power function with special reference to respiratory metabolism in fish. J. Fish. Res. Board Can., 26: 2643-2650.

Healey, M.C., 1978. The dynamics of exploited lake trout populations and implications for management. J. Wildl. Manage., 42: 307-328.

Jensen, A.L., 1976. Assessment of the United States' lake whitefish (Coregonus clupeaformis) fisheries of Lake Superior, Lake Michigan, and Lake Huron. J. Fish. Res. Board Can., 33: $747-759$.

Jensen, A.L., 1978. Assessment of the lake trout fishery in Lake Superior: 1929-1950. Trans. Am. Fish. Soc., 107: 543-549.

Jensen, A.L., 1984. PCB uptake and transfer to humans by lake trout. Environ. Pollut. (Ser. A), 34: 73-82.

Jensen, A.L., Spigarelli, S.A. and Thommes, M.M., 1982. PCB uptake by five species of fish in Lake Michigan, Green Bay of Lake Michigan, and Cayuga Lake, New York, Can. J. Fish. Aquat. Sci., 39: 700-709.

Neely, W.B., 1977. A material balance study of polychlorinated biphenyls in Lake Michigan. Sci. Total Environ., 7: 117-129.

Norstrom, R.J., McKinnon, A.E. and DeFreitas, A.S.W., 1976. A bioenergetics-based model for pollutant accumulation by fish. Simulation of $\mathrm{PCB}$ and methylmercury residue levels in Ottawa River yellow perch (Perca flavescens). J. Fish. Res. Board Can., 33: 248-267.

Schnoor, J.L., 1981. Fate and transport of dieldren in Coralville Reservoir: residues in fish and water following a pesticide ban. Science, 211: 840-842. 